"Information and communication technology as a primary tool for Sefako Makgatho Health Sciences University's statistics and operations research business"

AUTHORS Solly Matshonisa Seeletse

Solly Matshonisa Seeletse (2016). Information and communication technology as ARTICLE INFO a primary tool for Sefako Makgatho Health Sciences University's statistics and operations research business. Problems and Perspectives in Management, 14(3), 115-122. doi:10.21511/ppm.14(3).2016.12

DOI http://dx.doi.org/10.21511/ppm.14(3).2016.12

RELEASED ON

Friday, 29 July 2016

JOURNAL

"Problems and Perspectives in Management"

FOUNDER

LLC "Consulting Publishing Company "Business Perspectives"

NUMBER OF REFERENCES

0
NUMBER OF FIGURES

0

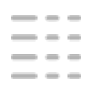

NUMBER OF TABLES

0

(c) The author(s) 2022. This publication is an open access article. 


\title{
Information and communication technology as a primary tool for Sefako Makgatho Health Sciences University's statistics and operations research business
}

\begin{abstract}
The Department of Statistics and Operations Reasearch (SOR) at the Sefako Makgatho Health Sciences University (SMU) in South Africa desires to increase its research output, as well as to provide high quality teaching and learning. Most SOR lecturers want to embrace technology and innovations, and also be competitive both regionally and globally. This can be achieved more effectively if they are trained in computer applications. Thus, they should be developed into critical citizens of the digital world. They should also be prepared to use information and communication technology (ICT) as a teaching and learning resource, as well as a research and community engagement backing. An innovation in academia should be backed by the lecturer. Thus, the main concern of this paper is to explore use of ICT as a business tool in SOR. Methodologies of the study were case study and thematic content analysis, and the data collection tool was a questionnaire. The study found that SOR was understaffed and could not provide full statistics (stats) training mainly in the statistical packages. The lecturers were all trained in ICT and the packages. They were all willing to use ICT in SOR activities. The computer laboratories were adequate for the student numbers at the time, even though some computers were not working. These laboratories showed to be poorly adequate for the envisaged growth of SOR. SOR would also need more lecturers for the future growth. The study recommends growth of SOR in lecturers and ICT facilities, at the least.
\end{abstract}

Keywords: curriculum, education, information and communications knowledge construction, lecturing, research, skills, students, technology.

JEL Classification: I2, O2, O3.

\section{Introduction}

Sefako Makgatho Health Sciences University (SMU) is a newly established (in January 2015) university on the former MEDUNSA campus of the University of Limpopo (UL). The campus was the former Medical University of Southern Africa (MEDUNSA). MEDUNSA was established in 1978 as a health and medical institution for the underprivileged communities. In 1988, it introduced the science programs also due to a need to empower the local communities. The sciences were growing in quality and quantity until the MEDUNSA merger with the former University of the North (UN) to form UL. Prior to this, Mathematics (Maths) and Statistics (Stats) courses were housed under the Department of Mathematics and Statistics. UL divided this department into the Department of Mathematics \& Applied Mathematics and the Department of Statistics \& Operations Research (SOR). SOR continued offering Stats courses only, despite the UL Turfloop campus having Operations Research (OR) as well. It also did not exploit its advantage of an SMU academic hospital to offer Biostatistics (Biostats) programs. Offering Biostats is a necessity for SOR, but it is important to prioritize best methods for the prevailing stats courses. In SMU, SOR is in the School of Pathology and Pre-Clinical Sciences (PPS). This placement of SOR is illogical and its support structures are ill-fated. SOR is also a subdivision in the broader

(C) Solly Matshonisa Seeletse, 2016.

Solly Matshonisa Seeletse, Ph.D., DBA, Professor \& HOD, Department of Statistics \& Operations Research, Sefako Makgatho Health Sciences University, Gauteng Province, South Africa.
Department of Mathematical and Physical Sciences. SOR business is teaching and learning to produce Stats graduates research, as well as community service. The future business shall include addition of courses in Stats and OR, and services to the university community such as statistical consultation and research supports. The departmental budget allocation is determined at PPS school level (i.e., by PPS director). There is a question as to whether the current PPS leadership knows the importance of the SOR subjects and the contribution they have in academia nationally and globally. A SOR challenge is that leaderships at school and departmental levels do not show full support of SOR in resourcing, such as staffing and financing, among others. Despite these constraints, SOR has over the past few years managed to evidence high quality teaching and its output, as well as research output that is not inferior to favored departments (in funding and staffing).

This paper advocates using ICT in conducting SOR's work. Historically, Stats lecturers have always been very few. SOR, therefore, inherited an understaffed division. Determination, capability and hard work, among others, however, ensured high performance in teaching and research. Modernity and external competition compels SOR to harness technology and innovations for sustained competitiveness. Students use technology on a daily basis. Hence, they do not have problems accessing ICT-driven instructions for education. However, Desimone (2009) technically states that the success of any educational innovation depends on academics' enthusiasm to implement the change. It 
is crucial that lecturers are primed, equipped with the knowledge and skills necessary for improved approaches (Darling-Hammond, 1999).

There have been initiatives of the digitization of syllabi in academia. In South Africa, leading institutions launched curriculum digitization to enable offering elearning (Okuttah, 2013). They also developed ICT curricula for teaching and research. Lecturers should be prepared for these initiatives. Their main concern is to increase pass rates, and, ultimately, the throughput rate. In cases where poor pass rates are obtained, departments and sometimes the lecturers in those courses are required to report and to indicate the initiatives they have embarked on to improve pass rates. This is because the institutions trust their judgement in admissions in which they admit students who qualify for admission and, thus, having a higher chance to succeed than to fail.

This study sought to establish the level of match between SOR lecturers' competence and students' enthusiasm to use ICT as a teaching and learning resource. Some departments and some lecturers in SMU believe that the pass rates should be controlled to less than $100 \%$. There were anecdotal reports of poor lecturing management in these departments. There were also allegations that the use of lecturing resources was poor. SOR's philosophy is that every lecturer should be equipped with more than adequate subject knowledge than the levels they facilitate, with facilitation skills and also knowledge in several teaching methodologies. They should, then, attempt to ensure that most of the students who have been admitted properly in a course, stand a good chance to pass. Where there are low pass rates, the lecturer or students may be the cause. Where a student shows a weakness, she/he is referred to student guardians for assistance to identify the weak points. These are addressed to help the students to cope. Where the lecturer is deficient as shown by recurrent high failure rates, they could be given crash courses or some in-service training to improve their teaching. Bitner and Bitner (2002) state that ICT is able to, and should deliver affluent, interactive teaching and learning resources to improve facilitation and introduce the innovations.

\section{Lecturer development and ICT}

A painstaking understanding of technology is crucial in ICT applications. This includes in research and teaching. SOR's idea to embrace ICT and innovations for competitiveness would be achieved more effectively if recruits into its academic ranks and support personnel (such as tutors and departmental fellows) were developed into critical citizens of the digital world. Lecturers and tutors should be able and willing to use ICT for teaching and learning. The lecturers should also use ICT for research. In this way it can enhance students' innovativeness and knowledge construction, research output (i.e., journal articles and more theses/dissertations) can be completed for research studies. According to Duffy and Jonassen (1992), constructivists emphasize that learning experiences should be genuine. They advocate for learning environments that enable students to construct their own knowledge. They condemn the cases that cause students to be ordinary recipients of knowledge. ICT usage can enhance knowledge construction at any level and for any application. However, the users at those levels must be equipped with ICT skills for those applications. This shows that training lecturers to use ICT as a tool for teaching and learning, research, student support, as well as office administration is critical for academic development at all levels. Lecturers can use the ICT skills they acquired to facilitate lectures, as well as in their daily activities.

\section{ICT worth in education}

2.1. ICT, an effective change agent. According to Pyla (2012), knowledge global nations used ICT to adapt, and ICT is the core of their education. Daniels (2002) also insinuates that developed countries depend on ICT. Leading economies cultivated and enhanced the working population into knowledge enabled working population using ICT. ICT is a multiplier for capacity building efforts of educational institutions. It also embraces high quality standards, and sustains a high economic growth rate through capacity building and people knowledge empowerment. It also promotes innovation. Basically, ICT is a change agent in education and society that promotes a suitable balance between content generations, research in critical areas relating skills and knowledge transfer. It connects and integrates knowledge with other countries' advancements.

2.2. Proposals for ICT incorporation in education. The worth of ICT use to enhance education is known globally. Ang'ondi (2010) proposed that nations should have national school policies to support teaching and learning. In another study, Wamakote (2010) also explained national governments' inclination to investing in ICT initiatives in their schools. Namalefe (2010) identified ICT as a leading factor for education advancement. Naseem (2010) proposed inclusion of suitable ICT infrastructure for education. Onguko and Hennesy (2010) deliberated on evolution of ICT initiatives in schools. To them, ICT was a future for education to embrace. Also, Henessy and Onguko (2010) confirmed that use of ICT in education improves quality and quantity of education at a much faster rate, and called for ICT incorporation in education. 
2.3. ICT, power of education transformation. ICT is a force that rehabilitates many aspects in life. Its impact in the past few decades is massive. Even though ICT is prevailing, Desai (2010) argues that the desired impact has not yet been achieved. The education is a socially oriented activity. Its contribution to quality education is acknowledged. There are numerous notable impacts of ICT on modern higher education. According to Abdullahi (2013), use of ICT in education enables a move to student-centred learning. Das Gupta and Haridas (2012) emphasize that global trends change speedily towards digital information. They express that the role of ICT in education is important. They envision that this importance will continue to grow and develop in future centuries. There are also potential future developments. For example, ICT is also transforming teacher-centred learning to competency based learning.

2.4. ICT heightens scholastic performance in education. The advancement of education has been by ICT influences (Harris, 2002). ICT has undeniably affected teaching, learning and research. According to Yusuf (2005), ICT hurries, augments, expands skills, inspires and involves students, assists in connecting learning experience to work practices, generates economic practicability for future workers, reinforces teaching and transforms educational institutions. In a fast changing world, basic education is essential for people to access and apply information. The speed and quality standards can be possible with ICT incorporation. This is because, according to Young (2002), ICT enhances the quality and accessibility of education at an alarming rate. ICT enhances the learning environment by presenting a completely original learning environment for students. Therefore, education requires a new, different skill set to be successful. The New Media Consortium (2007) identifies this skill as ICT, and enlightens that ICT varies processes of teaching and learning by incorporating rudiments of vitality to learning environments. Moreover, ICT helps students in their learning by improving the communication between them and the instructors. These show that ICT electrifies education. As a result, Valasidou and Bousiou (2005) conclude that ICT enhances the scholastic performance.

\section{Incorporating ICT in SOR curricula}

SMU has the blackboard system that was inherited from UL. Talks of blackboard being faced out and a new system for SMU introduced emerged in the SMU's first month of existence (which was January 2015). By October 2015, blackboard was still in use for the lecturers who had been introduced to it before SMU was established. Newer lecturers had no training in blackboard, and had no blackboard installed in their office machines. Amalgamating ICT in SOR curricula requires using ICT to facilitate lectures. The first basic requirement is computer literacy. In addition, lecturers are also required to be able to use the computer and applicable ICTs to teach. It is emphasized that the SOR lecturer is required to have a thorough understanding of the Statistics content to be able to unpack it and design ICT-supported lecture resources. Bitner and Bitner (2002) showed evidence that ICT usage in teaching and learning supports learning, increases learning outcomes significantly, and with many vital benefits. Among the benefits, ICT enables wide-ranging learning styles and individual learning differences. ICT also addresses diverse students' intellects, enhances construction of knowledge, engages the student, makes learning to be studentcentred, simplifies heavy lecturer loads, and eases data management. An encouraging aspect is that ICT supports the learning of all categories of students. It easily supports students with special needs and those who are gifted or especially talented in ways that optimize their learning. ICT also equates learning platforms in inclusive lecturing such that no disability can be detected.

SOR knows the ICT's immeasurable wealth in enhancing learning. SOR lecturers who surged through the ranks from student levels on merit had demonstrated capability to use ICT facilitating lectures. For ICT use in lectures, SOR lecturers need to have at least laptops. The challenges are that SOR had never heard the school leadership mentioning anything regarding teaching and learning, and their views on ICT use which is long overdue. SOR members know that modern technologies such as the computer and the internet provide the unsurpassed teaching and learning assets. The pressure from the Statistics world and current trends in education have stimulated SOR to use technology for effective instruction and learning management. ICT in SOR's education is useful for several purposes, the leading ones being superior facilitation of lectures and effective management of students' records.

To express the role of ICT in SOR's business, one should consider that modern technology (such as the computer) is used by lecturers to process students' assessment results. A computer enables the lecturer to use original marks to develop the percentages, rank and rate the students, grade student results and develop z-scores for conducting statistical test hastily and easily. It is also used to create instructional materials, and to locate convenient educational resources on the internet for lecturing. In addition, ICT can develop and enhance students' creativity and innovation by making their learning to be interactive. Therefore, ICT eases the educational process. It also generates challenging 
learning problems for students provides alternatives for problem solving and enhances the development of critical thinking skills. The internet enables interconnectivity with peers and experts in the same field. It also eases communication when information exchanges are required. IT facilitates discussions, chats and virtual conference attendances even with overseas platforms. It enables dialogues on topical educational issues and in e-learning. For students, ICT increases achievement, and nurtures creativity, innovation, motivation, as well as enthusiasm. In SOR, students receive immediate feedback and also receive individualized instruction. These are the bases of high student pass rates in SOR.

Technology is necessary when teaching Statistical software packages. Computer-aided learning can ensure the usage of the software packages. Multimedia software provides students a rich learning environment that accommodates their needs by providing applications, examples of treating concepts, and connecting with mathematics principles for interpretation after data analyses. Bitner and Bitner (2002) enlighten that computer simulations and animations are useful in explaining and illustrating difficult concepts, and for making abstract knowledge concrete in many subject areas. In Statistics, graphical displays in descriptive statistics and forecasts developed in time series analyses can be demonstrated. Computer games may be developed to improve students' knowledge in areas such as binomial distributions, in multivariate statistics demonstrating dimensions through graphics, and also for students' enjoyment.

ICT also has an e-learning version for student support when there is no lecturer-student contact such as in the evenings, holidays and during weekends. When using the e-learning packages, networked computers can facilitate interaction between students and their lecturers. Students can pose questions and obtain answers instantly. This enables students to participate effectively in the learning process. In addition, the lecturer can download or upload materials from the internet for students, and make available print and electronic forms for students. In e-learning, students can interact with the lecturer, and with each other. The e-learning mode also provides an extensive international collaboration opportunity for students and lecturers through web chatting, posting of assignments, online student-to-student dialogues and conversation settings (Bitner \& Bitner, 2002).

The ICT use in SOR consists of facilitation using various technologies, including for student support. This covers email and the internet, the various packages such as Microsoft Word and Excel, and Adobe reader, among the software packages. There can also be cellular phones for Facebook and other information sharing. In addition, the core SOR software packages taught and expected to be known by every statistician are SAS, SPSS, and, in some instances, STATA. Due to limited time, space and lecturers, SOR presents these software packages to students majoring in stats at the third year BSc and BSc Honours levels. The first and second year BSc students are only minimally exposed to the packages, but no intense training is given.

Furthermore, the lecturers who were in SOR when this study commenced, together with the new ones who joined in October 2015, received a comprehensive SAS training by the SAS institute. Together in the training were some computer science lecturers who assist SOR in project supervision of BSc Honours students, and also do some research with SOR lecturers. All these were indications in SMU's SOR that ICT tools are valued in statistical core and support activities.

\section{Statement of the problem}

SOR was very understaffed on the academic side and had no administrative or professional support staff, that other PPS departments enjoyed. However, SOR still aspired to grow by offering Biostats and OR. It was offering courses at the Bachelor degree level. It also offered postgraduate degrees from the Bachelor's Honours, Master of Science and doctoral levels. The aspiration of SOR was to produce the unsurpassed quality of stats graduates, increase pass rates and produce publications in accredited research journals. The envisaged future of Biostats and OR was to have more markets than the original settings, due to Biostats' established appeal to graduates from the applied sciences other than Stats. SOR wanted to continue doing well while improving on each aspect, and also to sustain the improvements. These were not possible with human capabilities, and with limited staffing. ICT is the only existing resource. The preparedness of ICT use in SOR's business demanded a formal enquiry. The enquiry was aimed at finding out whether the SOR lecturers, tutors and students were prepared to take the ICT route, and the extent to which the resources available could enable full ICT mode in this business.

\section{Aim and objectives of the study}

The aim of the study was to determine the SOR needs for holistic approach to use ICT in a sustained form to serve current needs and also be able to manage the envisaged growth business patterns. The objectives of the study were to:

- determine the current SOR lecturer adequacy in ICT lecturing and research;

- ascertain the computer resources available for the current SOR student numbers; 
- determine the capabilities of SOR tutors in ICT use in student support; and

- to project the SOR's future ICT needs.

\section{Materials and methods}

The methodologies employed were case study on SOR and document analysis. Face-to-face debates were used to collect primary data. Some verbatim statements of lecturers were studied thoroughly, and the issues focused on were contemporary. They dealt mainly with answering the questions 'what' and 'how?' (Yin, 2009). The Stats content of lecturer qualifications was known to be adequate. Also, most of the lecturers were capable, as they were identified frontrunners among their groups during BSc Honours study, and were recruited, because they were the best. The document analysis focused on the certificates informing on the computer literacy levels and the extent to which they were trained in computers. The other part consisted of student course combinations on subject combinations mainly to determine if computer science was among the subjects the students took with Stats. A casestudy approach was found to be appropriate as it allowed for a detailed study of a selected case (SOR) critical to investigating the phenomenon of integrating ICT in the work of SOR (Creswell, 2009). Data were also collected from the tutors employed for student support in SOR. The tutors were students admitted to the BSc Honours degree program after being found suitable to be trained as expert statisticians by virtue of achieving high grades at the exit level of the Bachelor's degree, coupled with the relevant level of Mathematics achievement. There were also the Program and Qualification Mix documents prepared for Biostats and OR, which had the envisaged populations of students starting in the year 2018.

6.1. Population and sample. The target population of the study was a total of 198 SOR populace, consisting of four lecturers, three doctoral students,
14 MSc students, 20 BSc Honours, eight tutors and 149 undergraduate (59 first-year, 39 second-year \& 51 third-year) students. Computer laboratories (labs) were also checked to determine the numbers of useful computers, as well as the software and Stats packages available in them. The study used the entire study population (or census), because it was accessible and manageable.

6.2. Data collection and analysis. Data collection consisted of discussions with SOR employees, as well as sourcing from documents containing students' information. The collected data were analyzed and used to establish the levels at which SOR lecturers were using ICT in their work, and whether lecturers and tutors were equipped to integrate ICT in teaching and learning. The students were investigated on whether they had ICT tools, and how much they used them in learning Stats. The adequacy levels of the available labs were also investigated. Based on the envisaged growth of SOR, the findings were also used to establish the future requirements of SOR for ICT use. In addition, the data were used to establish whether the lecturers were willing to apply their computer skills in their own teaching. A Chi-square test was used to test if the respondent rank had any upshot on the lack of possession of the ICT knowledge qualities. All statistical tests were conducted at the 5\% significance level.

\section{Results}

Analysis shows that SOR students had ICT tools and used them in learning. These included the internet, Facebook and email. They used these for student support. Even during strikes and holidays the SOR students have access to study materials and their lecturers (including their tutors).

Table 1 below displays the results obtained regarding possession and access of ICT facilities such as email, the Internet, and Facebook.

Table 1 . People capacity and practice for SOR business

\begin{tabular}{|l|c|c|c|c|c|c|}
\hline & Population & Sample & Confirmed ICT adequacy & Has ICT tools & Using ICT & Willing to use ICT \\
\hline Lecturers & 5 & 4 & 4 & 4 & 4 & 4 \\
\hline Tutors & 8 & 8 & 8 & 8 & 8 & 8 \\
\hline PhD's & 3 & 3 & 3 & 3 & 3 & 3 \\
\hline MSc's & 14 & 8 & 8 & 8 & 8 & 8 \\
\hline Hons's & 20 & 20 & 20 & 20 & 20 & 20 \\
\hline $3^{\text {rd }}$ years & 51 & 51 & 51 & 49 & 49 & 49 \\
\hline $2^{\text {nd }}$ years & 39 & 39 & 31 & 29 & 29 & 25 \\
\hline $1^{\text {1st } y e a r s ~}$ & 59 & 59 & 43 & 39 & 39 & 35 \\
\hline
\end{tabular}

Table 1 shows that all the lecturers and tutors sampled were adequate in using ICT tools, had the tools, were using them and were also willing to continue using them. This is the case also with all the postgraduate students ( $\mathrm{PhD}, \mathrm{MSc}, \mathrm{BSc}$ Hons). This indicates that the practitioner and the backup in SOR had everything for the prevailing ICT needs. On the undergraduate segments, possession of the 
qualities seemed to fade with lower levels. The Chi-square test (Wackerly, Mendenhall \& Scheaffer, 2008) gives the null and alternative hypotheses for the test as:

$H_{0}$ : The respondent rank and ICT quality results are independent of each other.

$H_{\alpha}$ : The respondent rank and ICT quality results are not independent of each other.

Let $o_{i}$ denote the $i^{\text {th }}$ observed frequencies and $\mathrm{e}_{\mathrm{i}}$ the corresponding expected frequencies in a contingency table. When small $(<5)$ observed frequencies are involved, Simon (2002) recommends the Yates corrected Chi-square equation: $\chi^{2}=\sum_{i=1}^{k} \frac{\left(\left|o_{i}-e_{i}\right|-0.5\right)^{2}}{e_{i}}$

The degrees of freedom $(d . f$.$) is (c-1)(r-1)$ on a contingency table with $\mathrm{c}$ columns and $\mathrm{r}$ rows (Tabachnick \& Fidell, 2007). The rule is to reject the null hypothesis if at a given level of significance the calculated test statistic exceeds the critical value obtained from the table of Chi-square statistics. The extract from Table 1 is used for ' 0 ' and the corresponding Table of ' $\mathrm{e}$ ' is developed in a combined Table 1a with the last four responses on Table 1 denoted as ' 1 ', '2', '3', '4' for convenience. The test and its result follow.

Table 1a. Observed and expected people capacity and practice for SOR business

\begin{tabular}{|l|c|c|c|c|}
\hline \multicolumn{1}{|c|}{ '0' } & '1' & '2' & '3' & '4' \\
\hline Lecturers & 4 & 4 & 4 & 4 \\
\hline Tutors & 8 & 8 & 8 & 8 \\
\hline PhD's & 3 & 3 & 3 & 3 \\
\hline MSc's & 8 & 8 & 8 & 8 \\
\hline Hons's & 20 & 20 & 20 & 20 \\
\hline $3^{\text {rd } y e a r s ~}$ & 51 & 49 & 49 & 49 \\
\hline $2^{\text {nd }}$ years & 31 & 29 & 29 & 25 \\
\hline $1^{\text {st } y e a r s ~}$ & 43 & 39 & 39 & 35 \\
\hline
\end{tabular}

\begin{tabular}{|l|c|c|c|c|}
\hline \multicolumn{1}{|c|}{ ' $e$ ' } & '1' & '2' & '3' & '4' \\
\hline Lecturers & 4.20 & 4.00 & 4.00 & 3.80 \\
\hline Tutors & 8.40 & 8.00 & 8.00 & 7.60 \\
\hline PhD's & 3.15 & 3.00 & 3.00 & 2.85 \\
\hline MSc's & 8.40 & 8.00 & 8.00 & 7.60 \\
\hline Hons's & 21.00 & 20.00 & 20.00 & 19.00 \\
\hline $3^{\text {rd }}$ years & 51.98 & 49.50 & 51.98 & 51.98 \\
\hline $2^{\text {nd }}$ years & 29.93 & 28.50 & 28.50 & 27.08 \\
\hline $1^{\text {st }}$ years & 40.95 & 39.00 & 39.00 & 37.05 \\
\hline
\end{tabular}

The $\chi^{2}=\sum_{i=1}^{k} \frac{\left(\left|o_{i}-e_{i}\right|-0.5\right)^{2}}{e_{i}}=0.8883$, d.f. $=(c-1)(r-1)=(4-1)(8-1)=(3)(7)=21$, and the critical value $\chi_{0.05}^{2}=32.7$. The test statistic does not exceed the critical value. Hence, the hypothesis of independence is not rejected. This implies that there is no enough statistical evidence at the 5\% significance level that the responses of SOR team members depend on their ranks.

The adequacy levels of the available labs for SOR business were also investigated.

Table 2. Laboratory capacity for SOR business

\begin{tabular}{|l|c|c|c|c|}
\hline $\begin{array}{c}\text { Labs on SMU } \\
\text { campus }\end{array}$ & Capacity & $\begin{array}{c}\text { Level of } \\
\text { SOR usage }\end{array}$ & $\begin{array}{c}\text { MS } \\
\text { packages }\end{array}$ & $\begin{array}{c}\text { Stats } \\
\text { packages }\end{array}$ \\
\hline SOR & 20 & 17 & 17 & 17 \\
\hline Student residence & 52 & 24 & 24 & 19 \\
\hline BMS west & 80 & 74 & 70 & 72 \\
\hline BMS east & 51 & 50 & 48 & 45 \\
\hline Clin path building & 80 & 21 & 21 & 21 \\
\hline
\end{tabular}

The first four labs had large levels of SOR usage, and the packages were installed in them. In the clinical pathology building, the levels were too low (26.3\%). However, current SOR can be catered adequately with any of the first four labs. The Chi-square test has the null and alternative hypotheses for the test as:

$H_{0}$ : The lab capabilities are independent of the lab location.

$H_{\alpha}$ : The lab capabilities are not independent of the lab location.

The value of the test statistic (Bless, Higson-Smith \& Kagee, 2006) is given by the formula:

$$
\chi^{2}=\sum_{i=1}^{k} \frac{\left(o_{i}-e_{i}\right)^{2}}{e_{i}} \text {. }
$$

An extract from Table 2 is used for ' $\mathrm{o}$ ' and a corresponding Table of ' $\mathrm{e}$ ' is developed in a combined Table $2 \mathrm{a}$ with the last four responses denoted as ' 1 ', ' '2', '3' for convenience.

Table $2 \mathrm{~b}$. Observed and expected laboratory capacity for SOR business

\begin{tabular}{|l|c|c|c|}
\hline \multicolumn{1}{|c|}{ 'o' } & '1' & '2' & '3' \\
\hline SOR & 17 & 17 & 17 \\
\hline Student residence & 24 & 24 & 19 \\
\hline BMS west & 74 & 70 & 72 \\
\hline BMS east & 50 & 48 & 45 \\
\hline Clin path & 21 & 21 & 21 \\
\hline
\end{tabular}

\begin{tabular}{|l|c|c|c|}
\hline \multicolumn{1}{|c|}{ ' $e$ ' } & ' & '2' & '3' \\
\hline SOR & 17.567 & 17.000 & 16.433 \\
\hline Student residence & 23.078 & 22.333 & 21.589 \\
\hline BMS west & 74.400 & 72.000 & 69.600 \\
\hline BMS east & 49.256 & 47.667 & 46.078 \\
\hline Clin path & 21.700 & 21.000 & 20.300 \\
\hline
\end{tabular}


The $\chi^{2}=\sum_{i=1}^{k} \frac{\left(o_{i}-e_{i}\right)^{2}}{e_{i}}=0.736, \quad$ d.f. $=(c-1)(r-1)=$ $=(3-1)(5-1)=8$, and the critical value $\chi_{0.05}^{2}=15.5$. The test statistic does not exceed the critical value. Hence, the hypothesis of independence is not rejected. This implies that there is no enough statistical evidence at the 5\% significance level that the lab capabilities to serve SOR depend on the lab location.

Based on the envisaged growth of SOR, the findings were also used to establish the future requirements of SOR for ICT use. The envisaged student numbers were as follows:

Table 3. Envisaged annual numbers of students in planned new SOR programs

\begin{tabular}{|l|c|c|}
\cline { 2 - 3 } \multicolumn{1}{c|}{} & \multicolumn{2}{c|}{ Stream } \\
\hline Program & Biostats & OR \\
\hline BSc & - & 150 \\
\hline Certificate & 80 & - \\
\hline BSc Hons & 40 & 20 \\
\hline MSc & 32 & 8 \\
\hline PhD & 8 & 4 \\
\hline
\end{tabular}

The total useful ICT space for SOR business from Table 2 is for 186 students. This will be inadequate even for the BSc and certificate levels alone. Thus, growth in ICT facilities is necessary. In the next four to five years, the undergraduate alone will require close to 500 ICT units (230 new plus current 199 and its growth). The demand for SOR products has been ascertained to be high. Hence, if the SOR growth is supported, there will soon be a need for close to 700 ICT teaching and learning student spaces.

In addition, the data positively establish that lecturers were capable and willing to integrate ICT in their SOR activities.

\section{Discussion}

The results show that the SOR lecturers were adequate in lecturing and research using ICT tools. Some ICT facilities for SOR use were unusable. However, due to the limited numbers of students, the unusable spaces were not needed. Further, the unusable ICT spaces were in different buildings on campus. There was no statistical association on the location of unused ICT facilities for SOR business. Thus, apart from the lecturer adequacy, the study established the computer resources available for the SOR student numbers. The lecturers were capable of using ICT to facilitate and support SOR business.
There was also a sign of adequacy of lecturers to carry out future SOR business using ICT. The problem was that when growth of the student numbers materializes, there is a threat that the laboratory space for more SOR students would be less than adequate. The tutors were mostly students, pursuing postgraduate studies in SOR. They showed to be capable of using ICT for SOR student support.

Another problem was that the first and second year BSc students did not get any formal training. The reason was that lecturers were few, and there was no time to complete core work of confirmed stats majors. Hence, they were less prioritized on the packages. At the third year level, which is an exit and major level, the students were trained on the packages to prepare the SOR's future ICT needs. The lecturers were all trained in the statistical packages. They were fully literate on ICT and Microsoft packages. There was also instant support on any ICT matter due to the working relationship with computer science department in SMU.

\section{Conclusion}

The initiative to use ICT in SOR business is necessary, especially for the modern day. All the lecturers have been trained. They were all willing to use ICT and had already started to do so. The first two years of SOR courses were not part of the full stats packages training, but were also been lectured and supported using ICT resources. The growth of stats into new programs predicts future ICT inadequacy. This was in addition to the inadequacy at first- and second-year BSc. This shows that SOR was understaffed with regards to lecturers. The future growth of SOR, therefore, shows that understaffing was at both the existing undergraduate levels, as well as the entire various qualification programs in the streams of Biostats and OR.

\section{Recommendations}

The study recommends that SOR should

- solicit academic staffing for undergraduate (firstand second-year BSc) to ensure full training and student support with statistical packages;

- continue use of ICT in training students and undertaking research;

- continue with its growth plans in Biostats and OR, but should intensify lecturer growth to complement that growth; and

- seek SOR owned and controlled adequate-forfuture lab facilities to match the envisaged growth.

\section{References}

1. Abdullahi, H. (2012). The role of ICT in teaching science education in schools, International Letters of Social and Humanistic Sciences, 19, pp. 217-223.

2. Ang'ondi, K.E. (2010). National policy for using ICT to support teaching and learning in primary and secondary 
schools in East Africa, pp. 6-17. In Hennessy, S. \& Onguko, B. (eds.) Developing use of ICT to enhance teaching and learning in East African schools: a review of the literature. Pakistan: The Aga Khan University.

3. Bitner, N. \& Bitner, J. (2002). Integrating technology in the classroom: Eight Keys to Success, Journal of Technology and Teacher Education, 10 (1), pp. 95-100.

4. Bless, C., Higson-Smith, C. \& Kagee, A. (2006). Fundamentals of social research methods: An African Perspective. Cape Town: Juta \& Co.

5. Creswell, J.W. (2009). Research Design. Case Study. California: SAGE publications.

6. Daniels, J.S. (2002). 'Foreword' in Information and Communication Technology in Education, A Curriculum for Schools and Program for Teacher Development. Paris: UNESCO.

7. Darling-Hammond, L. (1999). Teacher quality and school achievement: A review of state policy evidence. Seattle, WA: Centre for Study of Teaching and Policy.

8. Das Gupta and Haridas. (2012). The role of ICT in improving the quality of school education in Bihar. Working Paper. IGC India-Bihar: Oxford University Press.

9. Desai, S. (2010). Role of information communication technologies in education. Proceedings of the 4th National Conference; INDIACom-2010 Computing For Nation Development, February 25-26 ${ }^{\text {th }}$, 2010, Bharati Vidyapeeth's Institute of Computer Applications and Management, New Delhi, India.

10. Desimone, L. (2009). Improving Impact Studies of Teachers' Professional Development: Towards Better Conceptualizations and Measures. Educational Researcher. American Research Association: SAGE publications. Available at: http://er.aera.net. Accessed on 24 September 2014.

11. Duffy, T. \& Jonassen, D. (1992). Constructivism: New implications for instructional technology. NJ: Hillsdale, Erlbaum. Kenya Institute of Education (KIE) (2005). ICT Teachers' Guide.

12. Harris, S. (2002). Innovative pedagogical practices using ICT in schools in England, Journal of Computer Assisted Learning, 18, pp. 449-458.

13. Hennessy, S. \& Onguko, B. (2010). Implications for developing educational uses of ICT in East Africa. In Hennessy, S. \& Onguko, B. (eds.) Developing use of ICT to enhance teaching and learning in East African schools: a review of the literature. Pakistan: The Aga Khan University, pp. 96-101.

14. Namalefe, S. (2010). Curriculum and school-related factors influencing integration of ICT in primary and secondary classrooms: evidence from Uganda, Kenya and Tanzania. In Hennessy, S. \& Onguko, B. (eds.) Developing use of ICT to enhance teaching and learning in East African schools: a review of the literature. Pakistan: The Aga Khan University, pp. 57-66.

15. Naseem, A. (2010). Physical and other related external factors affecting the use of ICT in primary and secondary schools in Sub-Saharan Africa. In Hennessy, S. \& Onguko, B. (eds.) Developing use of ICT to enhance teaching and learning in East African schools: a review of the literature. Pakistan: The Aga Khan University, pp. 48-56.

16. New Media Consortium. (2007). Horizon Report. Available at: www.nmc.org/pdf/2007_Horizon_Report.pdf. Accessed on October $1^{\text {st }}, 2015$.

17. Okuttah, M. (2013). Digital Age: Huge steps towards e-learning in schools, The Daily Nation, 17 October, p. 50.

18. Onguko, B. \& Hennessy, S. (2010). Key past and current initiatives supporting the use of ICT in schools in African Commonwealth countries. In Hennessy, S. \& Onguko, B. (eds.) Developing use of ICT to enhance teaching and learning in East African schools: a review of the literature. Pakistan: The Aga Khan University, pp. 28-47.

19. Pyla, A. (2012). ICT as a change agent for higher education and society, IJCA Proceedings on EGovernance and Cloud Computing Services, 1, pp. 25-30.

20. Simon, M.K. (2002). Probability distributions involving Gaussian random variables. New York: Springer.

21. Tabachnick, B.G. \& Fidell, L.S. (2007). Using multivariate statistics. $5^{\text {th }}$ edition. Boston: Pearson Education, Inc. / Allyn and Bacon.

22. Valasidou, A., Sidiropoulos, D., Hatzis, T. \& Bousiou-Makridou, D. (2005). Guidelines for the Design and Implementation of E-Learning Programs, Proceedings of the IADIS. International Conference IADIS E-Society 2005, 27-30 June, Qawra, Malta.

23. Wackerly, D., Mendenhall, W. \& Scheaffer, R.L. (2008). Mathematical statistics with applications. $7^{\text {th }}$ edition. Belmont, CA, USA: Thomson Higher Education.

24. Wamakote, L. (2010). National government investment in ICT initiatives in primary and secondary schools in East Africa. In Hennessy, S. \& Onguko, B. (eds.) Developing use of ICT to enhance teaching and learning in East African schools: a review of the literature. Pakistan: The Aga Khan University, pp. 18-27.

25. Yin, R.K. (2009). Case study research: Design and methods. $4^{\text {th }}$ edition. Singapore: SAGE Publications.

26. Young, J. (2002). The 24-hour professor, The Chronicle of Higher Education, 48 (38), pp. 31-33.

27. Yusuf, M.O. (2005). Information and communication education: Analyzing the Nigerian national policy for information technology, International Education Journal, 6 (3), pp. 316-321. 